\title{
The addition of functional task-oriented mental practice to conventional physical therapy improves motor skills in daily functions after stroke*
}

\author{
Clarissa C. Santos-Couto-Paz ${ }^{1,2}$, Luci F. Teixeira-Salmela ${ }^{3}$, \\ Carlos J. Tierra-Criollo ${ }^{2,4}$
}

\begin{abstract}
Background: Mental practice (MP) is a cognitive strategy which may improve the acquisition of motor skills and functional performance of athletes and individuals with neurological injuries. Objective: To determine whether an individualized, specific functional task-oriented MP, when added to conventional physical therapy (PT), promoted better learning of motor skills in daily functions in individuals with chronic stroke ( $13 \pm 6.5$ months post-stroke). Method: Nine individuals with stable mild and moderate upper limb impairments participated, by employing an $\mathrm{A}_{1}-\mathrm{B}_{-} \mathrm{A}_{2}$ singlecase design. Phases $\mathrm{A}_{1}$ and $\mathrm{A}_{2}$ included one month of conventional PT, and phase $\mathrm{B}$ the addition of MP training to PT. The motor activity log (MAL-Brazil) was used to assess the amount of use (AOU) and quality of movement (QOM) of the paretic upper limb; the revised motor imagery questionnaire (MIQ-RS) to assess the abilities in kinesthetic and visual motor imagery; the Minnesota manual dexterity test to assess manual dexterity; and gait speed to assess mobility. Results: After phase $A_{1}$, no significant changes were observed for any of the outcome measures. However, after phase B, significant improvements were observed for the MAL, AOU and QOM scores $(p<0.0001)$, and MIQ-RS kinesthetic and visual scores $(p=0.003 ; p=0.007$, respectively). The significant gains in manual dexterity $(p=0.002)$ and gait speed $(p=0.019)$ were maintained after phase $\mathrm{A}_{2}$. Conclusions: Specific functional task-oriented MP, when added to conventional PT, led to improvements in motor imagery abilities combined with increases in the AOU and QOM in daily functions, manual dexterity, and gait speed.
\end{abstract}

Keywords: mental practice; motor imagery; rehabilitation; physical therapy; learning.

\section{HOW TO CITE THIS ARTICLE}

Santos-Couto-Paz CC, Teixeira-Salmela LF, Tierra-Criollo CJ. The addition of functional task-oriented mental practice to conventional physical therapy improves motor skills in daily functions after stroke. Braz J Phys Ther.2013 Nov-Dec; 17(6):564-571. http://dx.doi.org/10.1590/S1413-35552012005000123

\section{Introduction}

Residual impairments and functional limitations are the major causes of social restrictions and permanent disabilities in individuals with stroke ${ }^{1}$. Recovery of the paretic upper limb (UL) is crucial to perform activities of daily living, but it is often variable and incomplete, and about $65 \%$ of individuals with chronic stroke had functional limitations related to their $\mathrm{UL}^{2}$. Therefore, improved rehabilitation strategies are needed, particularly in the chronic stages, when patients are discharged from rehabilitation and recovery is often limited ${ }^{3}$.

Mental Practice (MP) is a method by which the internal reproduction of a given motor act is extensively repeated with the intention of improving performance ${ }^{4}$. Braun et al. ${ }^{5}$ suggested that during MP, within a given context, an internal representation of the movement is activated and its execution is mentally repeated without physical activity. MP is used for goal-oriented improvement or stabilization of a given movement and is considered a mental rehearsal of kinesthetic and/or visual properties of movements ${ }^{6}$ and directly related to the activation of the motor and somatosensory cortical areas ${ }^{4}$. This intervention can be used to promote the relearning of daily tasks for people in various stages of stroke $e^{6,7}$. Thus, MP is a cognitive strategy which may benefit the acquisition of motor skills and the functional performance of athletes and individuals with neurological injuries.

However, controversies still persist regarding the effectiveness of this intervention ${ }^{8}$, given that many variables $^{9}$, such as the nature of the motor tasks, the

${ }^{1}$ Faculdade de Ceilândia, Universidade de Brasília (UNB), Brasília, DF, Brazil

${ }^{2}$ Graduate Program in Neurosciences, Institute of Biological Sciences, Universidade Federal de Minas Gerais (UFMG), Belo Horizonte, MG Brazil ${ }^{3}$ Physical Therapy Department, UFMG, Belo Horizonte, MG, Brazil

${ }^{4}$ Biomedical Engineering Program (COPPE), Universidade Federal do Rio de Janeiro (UFRJ), Rio de Janeiro, RJ, Brazil

*This abstract was published in the Journal of Neurologic Physical Therapy, the Annals of the $2^{\text {nd }}$ COBRAFIN, and the $8^{\text {th }}$ World Stroke Congress. Received: 12/10/2012 Revised: 06/07/2013 Accepted: 06/18/2013 
practice intensity, duration, and the learning stages, were not taken into account when interpreting the results of MP training ${ }^{10}$. Variables related to the individuals also need to be considered, such as their dominant UL, which could directly impact the performance and motor training ${ }^{11}$. There is also evidence that individuals with better imagery, i.e. people who produce the autonomic nervous system responses in most imagery session conditions, had greater increases in motor performance than other subjects ${ }^{12}$ through active compensatory neural networks ${ }^{13}$. In addition, studies that examined the motor learning of specific tasks have been scarcely described, which make it difficult to apply this approach within clinical contexts.

Most studies analyzed the influence of specific and isolated movement-based $\mathrm{MP}^{12}$. A recent study suggested that task-oriented MP may promote neuroplasticity ${ }^{14}$, increase functional capacity, and generate greater cortical changes, and promote better motor learning to improve motor skills in daily functions. According to Jackson et al. ${ }^{12}$, the motor, cognitive, and psychological factors contribute to the outcome of various forms of practice, including MP. They proposed that up to three distinct levels of learning processes could contribute and interact with each other during the practice of a given activity: (1) The declarative knowledge refers to the knowledge required prior to performing a given motor task, such as the kinematic component (KC) involved in the movement production; (2) The non-conscious processes are related to aspects of the skills which are not directly accessible to verbal descriptions, such as the activation or inhibition of different muscles throughout the task; and (3) The physical execution refers to the activity necessary to carry out the intended action. According to this model, the use of declarative knowledge can be more important at the beginning of the training than when the task is well learned. Therefore, MP with motor imagery requires that the subjects have all the necessary declarative knowledge regarding the various $\mathrm{KC}$ of the tasks before performing them. However, the rehearsing of the 'activities of daily living (ADL) and the home environment with motor imagery could also give access to the non-conscious processes involved in learning the skilled behavior.

Therefore, the objective of this study was to verify whether an individualized, specific functional taskoriented MP, when added to conventional physical therapy (PT), promoted better learning of motor skills in ADL in individuals with chronic stroke. It was hypothesized that the addition of functional MP to conventional PT would result in greater functional gains.

\section{Method}

\section{Subjects}

Sixteen volunteers were recruited from the PT out-patient clinics of Santa Casa Hospital, of the city of Bom Despacho, MG, Brazil, according on the following criteria: had ages between 20 and 60 years; time since the onset of a unilateral stroke of at least six months; had impairments of their dominant UL; had no cognitive deficits, as determined by the cut-off scores $>18$ in the modified Mini-Mental State Examination ${ }^{15}$; demonstrated the ability to actively flex the paretic wrists and the metacarpophalangeal and interphalangeal joints of the index and thumb of at least $10^{\circ}$; and had received prior strengthening and stretching-based conventional PT. Individuals were excluded if they had scores $\geq 3$ on the modified Ashworth Scale ${ }^{16}$; excessive pain on their paretic UL (scores $\geq 4$ on the 10-point visual analog scale); had difficulty in performing imagery, as assessed by the revised motor imagery questionnaire (MIQ-RS) ${ }^{17}$; and other neurological disorders. All participants provided consent based upon ethical approval (\# 0222.0.203.000-11) from the Research Ethical Committee of the Universidade Federal de Minas Gerais (UFMG), Belo Horizonte, MG, Brazil. A sample size of at least eight subjects was calculated to reach $80 \%$ of power and an effect size of 1.5 , based upon the primary outcome measure (Motor Activity $\log$ ) with a significance level of $5 \%$.

\section{Testing and design}

After screening and obtaining consent, demographic, anthropometric, and clinical information were collected for all participants. Their stages of motor impairments were assessed by the Orpington Prognostic Scale ${ }^{18}$ and the tone of the elbow and wrist flexor muscles was quantified by the modified Ashworth Scale, at rapid speeds ${ }^{16}$.

The $\mathrm{A}_{1}-\mathrm{B}-\mathrm{A}_{2}$ single case design was applied as follows: Phase $A_{1}$ - Conventional PT; phase $\mathrm{B}-\mathrm{MP}+\mathrm{PT}$; and phase $\mathrm{A}_{2}$ - conventional PT. Each of the training phases lasted four weeks. The outcome measures were obtained at baseline ( $\left(1^{\text {st }}\right.$ assessment $)$, after one-month of conventional PT ( $2^{\text {nd }}$ assessment $)$, after one month of MP+PT ( $3^{\text {rd }}$ assessment), and after one month of PT alone ( $4^{\text {th }}$ assessment) (Figure 1).

\section{Primary outcome measures}

Based upon previous functional training studies, the primary outcome measure was determined 


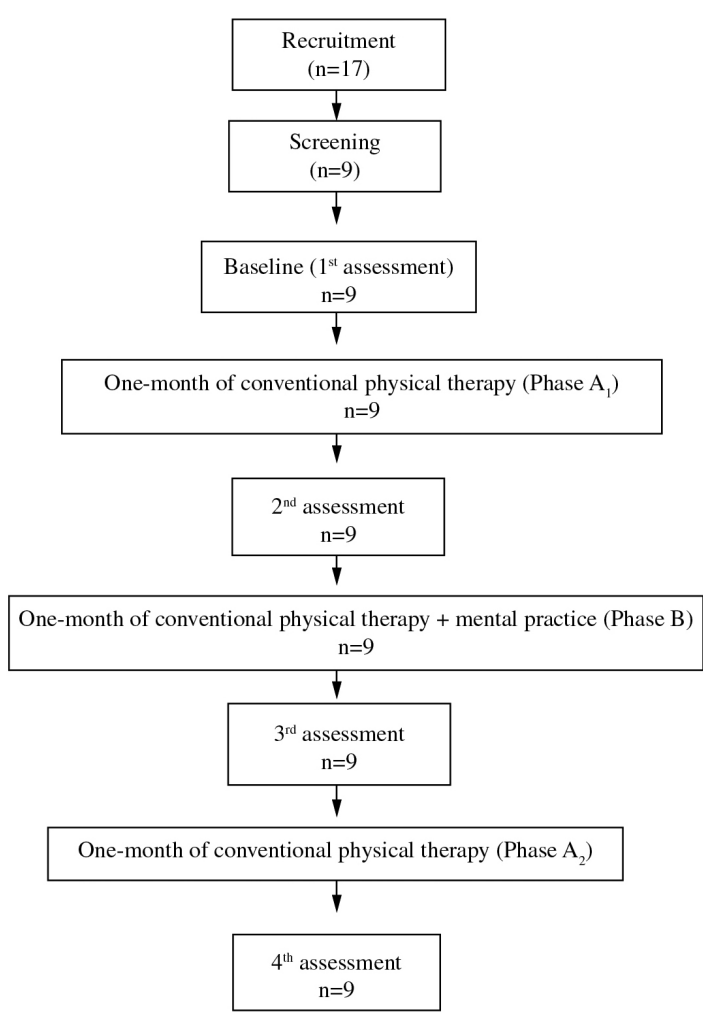

Figure 1. Flow diagram of the study.

by both the amount of use (AOU) and quality of movement (QOM) scales of the Brazilian version of the motor activity log (MAL-Brazil) ${ }^{19,20}$. This scale contains 30 items related to routine activities undertaken with the most-affected UL. The MAL has shown to be valid and demonstrated adequate test-retest reliability ${ }^{19}$. The participants were questioned regarding how much and how well they performed their daily activities with their paretic $\mathrm{UL}^{19}$. The MAL total scores were obtained by the sum of the responses divided by the number of the assessed items, which ranged from zero to five, with higher scores demonstrating better performances $^{19,20}$.

The MIQ-RS is a questionnaire constructed to assess movement imagery ability and has shown adequate validity and test-retest reliability ${ }^{17}$. The MIQ-RS requires movements of both the upper and lower limbs to assess the ability of imagining gross motor movements and includes movements related to their ADL. It is composed of visual and kinesthetic sub-scales, with each having seven items. Each item is rated on a 7-point scale, ranging from $1=$ very hard to see/feel to $7=$ very easy to see/feel.

\section{Secondary outcome measures}

Secondary outcome measures included the Minnesota Manual Dexterity Test (MMDT) and gait speed. The MMDT is a short version of the Minnesota Dexterity Tests ${ }^{21}$ and consists of two timed sub-tests ("placing" and "turning tests") to assess the required manual dexterity to turn and/or place 60 short, round blocks with one or both hands. In this study, the placing sub-test ${ }^{21}$ was used to assess the ability to handle objects, measured by the time required to complete the task ${ }^{22}$. The MMDT has been used to measure the degrees of disability and/ or patient progress during specific training, as well as for the qualification of tasks which require manual dexterity and daily activities ${ }^{22}$. The Brazilian version of the MMDT demonstrated adequate psychometric properties $^{22}$.

\section{Gait speed}

To analyze the influence of specific functional task-oriented MP on mobility, the 10-meter gait speed test was employed ${ }^{23}$. It measures the time, in seconds, required to walk 10 meters at the subject's preferred speed, and the time was converted to gait speed $(\mathrm{m} / \mathrm{s})$.

\section{Interventions}

\section{Mental practice}

One-on-one 30-minute MP training sessions were provided three days per week for four weeks, totaling 12 sessions. The training was performed in a quiet room with objects which simulated ADL and was conducted from a first-person perspective. The individuals were instructed to imagine, as if they were performing the tasks themselves, without actually executing them. The trained tasks, which were identified during the initial assessments, were selected according to the individuals objectives with gradual increases in the task constraints related to the number of the KC. The training started with the simplest task and progressed to the most difficult ones, focusing on the grasp and grip of certain objects. This type of training takes into account not only the principles of intensity and specificity, but also the motor learning principles. During the early stages of learning, the individuals used cognitive strategies, such as attention, and after training, they no longer needed to focus their attention on the single movement, but on the task as a whole, which made the movement's execution automatic ${ }^{24}$.

To facilitate training, the tasks were divided into specific $\mathrm{KC}$, which were identified by the individuals 
during their execution or their attempts. Prior to training, the subjects were instructed to perform or attempt to perform a given task, and pay attention to how they performed it. Then, they were instructed to divide the task into parts, the $\mathrm{KC}$ and to describe how well they performed them and the difficulties they had during their execution. For example, to perform the grasp, the first participant divided the task into four KCs: "Elevate my shoulder, stretch my elbow, place my hand over the object, and grasp the object". Such training is believed to promote intrinsic feedback for the individuals, as they are able to identify their errors while performing the task and adapt their movement patterns. It also allowed the individuals to develop strategies for specific movements, once they had performed the movement and could understand the characteristics of the environment and its restrictions, therefore generating specific movement patterns. In other studies $^{7,9,10}$, the physical therapist demonstrated the movement to be imagined by the patient, but in the present study, there was no guidance, since each person had different perceptions and various physical characteristics. Once the individuals were able to identify, understand, and describe the $\mathrm{KC}$ and the task constraints, they were instructed to imagine the task 10 times. After this, they were instructed to describe and imagine the whole task 10 times. The use-dependent plasticity of the central nervous system is attributed to both dose-dependent and context-dependent effects of interventions referred to as enriched environments and rehabilitation ${ }^{25}$.

Soon after the MP training, the subjects were asked to describe each of the $\mathrm{KC}$ tasks, perform each task, and then try to execute them as a whole, using what they previously learned. Later, they were asked to describe their degrees of difficulty in performing motor imagery, according to the MIQ-RS scale and rate their efforts according to the Borg scale $(0-10)^{26}$. Subjects were instructed to maintain a relaxed position throughout the training and, if they lost their concentration, training was temporarily interrupted.

\section{Conventional physical therapy intervention}

Each 30-minute session of the conventional PT intervention consisted of five minutes of mild stretching, 20 minutes of strengthening exercises, and five minutes of muscular relaxation. During each session, emphasis was put on stretching the flexor muscles and on strengthening the paretic flexor/ extensor muscle groups of the shoulder, elbow, and wrist joints, in addition to the scapular muscles.

\section{Data analyses}

Descriptive statistics and tests for normality were carried out for all outcome variables, using the SPSS for Windows software (version 13.0). Repeated measure analyses of variance (ANOVAs), followed by pre-planned contrasts, were used to determine differences between the training phases with a significance level of $5 \%$.

\section{Results}

\section{Participants characteristics}

Seventeen subjects were recruited, but eight were excluded for the following reasons: Two were enrolled in other motor rehabilitation interventions, one had insufficient UL motor function; two had scores $\geq 3$ on the modified Ashworth Scale; one had an unstable cardiac condition; and two had difficulty in performing imagery. Thus, nine subjects (three men) with a mean age of $42.2 \pm 12.2$ years (ranging from 23 to 54), a mean time since the onset of the stroke of $13 \pm 6.5$ months (ranging from 7 to 24), and mild to moderate impairments, completed all tests and training. The subjects had their dominant UL affected ULs (four left and five right).

\section{Outcome measures}

\section{MIQ Scores}

Significant differences between the phases were found for the MIQ-RS visual and kinesthetic scores $(F=10.10, p=0.007$; power $=0.87$ and $F=16.08$, $p=0.003$; power $=0.95$ ). As shown in Table 1 and Figure 2, no significant differences were found between the scores obtained at the $1^{\text {st }}$ and $2^{\text {nd }}$ assessments in the visual and kinesthetic scores $(1.26<F<1.51 ; 0.10<p<0.25)$. Significant differences were observed between the scores obtained at the $2^{\text {nd }}$ and $3^{\text {rd }}$ assessments for the visual score $(F=12.03$; $p=0.008)$ and kinesthetic scores $(F=17.56 ; p=0.003)$. However, these gains were not maintained at the $4^{\text {th }}$ assessment $(11.36<F<12.99 ; 0.01<p<0.007)$. These results indicated that the MP training resulted in improved motor imagery abilities.

\section{MAL scores}

ANOVA revealed significant differences between the phases for both the AOU and QOM scales $(F=33.71 ; p<0.0001$; power $=0.999$ and $F=35.72$; $p<0.0001$; power $=1.0$ ). The contrasts revealed no 
Table 1. Mean (standard deviation) values of the outcome measures obtained for all of the evaluated phases and comparisons between the phases.

\begin{tabular}{|c|c|c|c|c|c|}
\hline \multicolumn{2}{|c|}{ Variables } & \multirow{2}{*}{$\begin{array}{c}\text { Baseline } \\
23.50(08.35)^{\mathrm{a}}\end{array}$} & \multirow{2}{*}{$\begin{array}{c}\text { After } \mathbf{A}_{1} \text { phase } \\
24.50(09.17)^{\mathrm{a}}\end{array}$} & \multirow{2}{*}{$\begin{array}{c}\text { After B phase } \\
40.50(7.22)^{\mathrm{b}}\end{array}$} & \multirow{2}{*}{$\begin{array}{c}\text { After } \mathbf{A}_{2} \text { phase } \\
37.10(8.69)^{\mathrm{c}}\end{array}$} \\
\hline MIQ & Kinestthesic & & & & \\
\hline (score) & Visual & $28.89(10.12)^{\mathrm{a}}$ & $30.00(10.50)^{\mathrm{a}}$ & $41.11(8.39)^{\mathrm{b}}$ & $38.22(9.04)^{\mathrm{c}}$ \\
\hline \multirow{2}{*}{$\begin{array}{l}\text { MAL } \\
\text { (score) }\end{array}$} & QOM & $1.00(0.58)^{\mathrm{a}}$ & $1.00(0.56)^{\mathrm{a}}$ & $2.94(1.30)^{\mathrm{b}}$ & $2.97(1.29)^{\mathrm{b}}$ \\
\hline & $\mathrm{AOU}$ & $0.97(0.71)^{\mathrm{a}}$ & $0.98(0.68)^{\mathrm{a}}$ & $2.70(1.42)^{\mathrm{b}}$ & $2.75(1.41)^{\mathrm{b}}$ \\
\hline \multicolumn{2}{|c|}{ MMDT (pieces/min) } & $10.53(9.31)^{\mathrm{a}}$ & $11.13(10.10)^{\mathrm{a}}$ & $16.43(12.84)^{\mathrm{b}}$ & $15.97(12.48)^{b}$ \\
\hline \multicolumn{2}{|c|}{ Gait speed (m/s) } & $0.75(0.41)^{\mathrm{a}}$ & $0.75(0.42)^{\mathrm{a}}$ & $0.97(0.52)^{\mathrm{b}}$ & $0.91(0.71)^{\mathrm{b}}$ \\
\hline
\end{tabular}

$\mathrm{MIQ}=$ motor imagery questionnaire; $\mathrm{MAL}=$ motor activity $\log$; $\mathrm{QOM}=$ quality of movement; $\mathrm{AOU}=$ amount of use; MMDT=Minnesota manua dexterity test. For each column, different letters represent statistical significance between each phase.

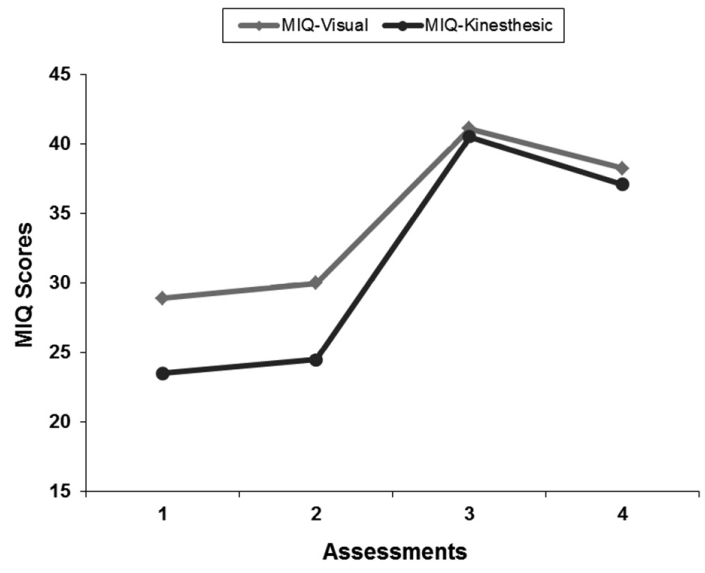

Figure 2. Visual and kinesthetic MIQ scores obtained at baseline (1); after phase $\mathrm{A}_{1}(2)$; after phase $\mathrm{B}(3)$; and after phase $\mathrm{A}_{2}$ (4).

significant differences between the scores obtained at the $1^{\text {st }}$ and $2^{\text {nd }}$ assessments $(0.14<F=0.16$; $0.70<p=0.91)$. However, significant differences were observed after the addition of MP regarding the AOU and QOM scales $(F=31.56 ; p=0.001$ and $F=36.32$; $p<0.0001$, respectively). These gains were maintained at the $4^{\text {th }}$ assessment $(0.30<F<0.50 ; 0.49<p=0.60)$. These results indicated that the gains in the subjects' perceptions regarding the AOU and QOM of their paretic UL persisted after the withdrawal of the MP intervention (Table 1 and Figure 3).

\section{MMDT and gait speed}

As shown in Table 1 and Figure 4, significant differences were found between the scores obtained for all phases for the MMDT $(F=18.87$; $p=0.002$; power $=0.97)$ and gait speed $(F=6.88$; $p=0.02$; power $=0.73$ ). The contrasts showed no significant differences between the MMDT and gait speed obtained at the $1^{\text {st }}$ and $2^{\text {nd }}$ assessments $(F=2.33 ; p=0.17$ and $F=0.008 ; p=0.93)$. However,

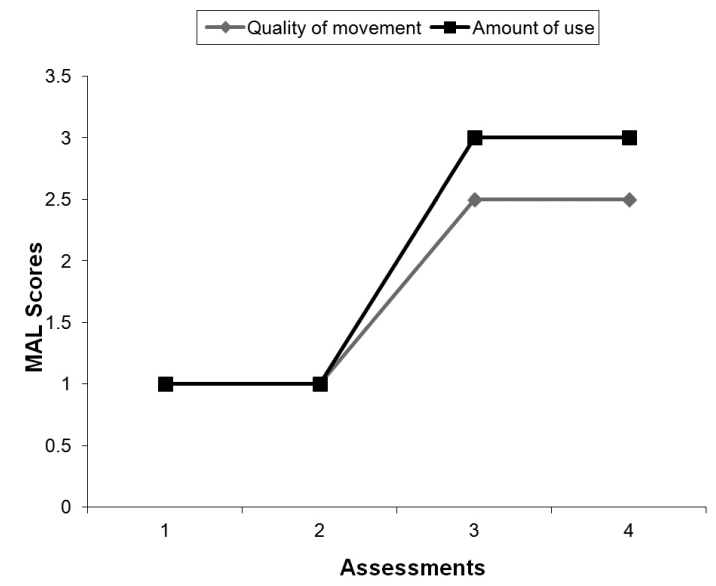

Figure 3. MAL scores of the quality of movement and amount of use scales obtained at baseline (1); after phase $A_{1}(2)$; after phase $\mathrm{B}$ (3); and after phase $\mathrm{A}_{2}$ (4).

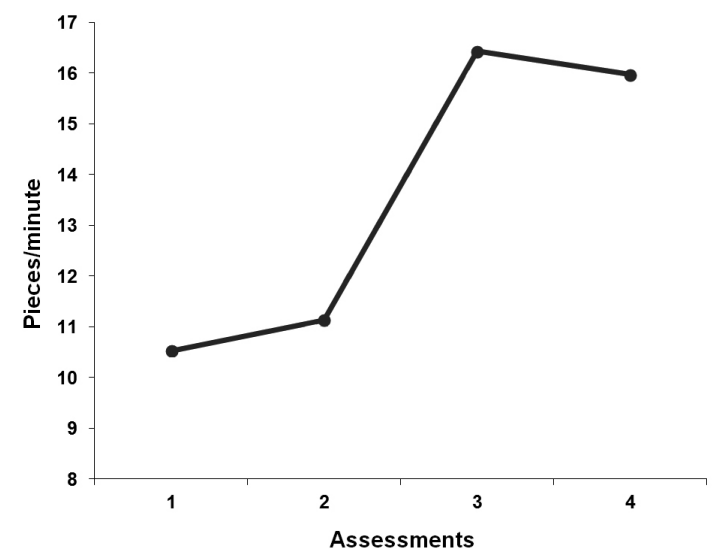

Figure 4. Minnesota manual dexterity test (MMDT) (pieces/min) obtained at baseline (1); after phase $\mathrm{A}_{1}$ (2); after phase B (3); and after phase $A_{2}$ (4).

significant differences were observed between the $2^{\text {nd }}$ and $3^{\text {rd }}$ assessments for both the MMDT and gait speed $(F=22.18 ; p=0.002$ and $F=9.47 ; p=0.015$, respectively). These gains were maintained at the $4^{\text {th }}$ 
assessment $(F=4.98 ; p=0.06$ and $F=2.71 ; \mathrm{p}=0.14$ ), suggesting that the addition of MP training resulted in manual dexterity and mobility gains.

\section{- Discussion}

MP has emerged as a non-invasive strategy to increase the use and function of the paretic UL, even years after stroke ${ }^{14}$. Previous MP studies have hypothesized that the repetitive use of the paretic UL and the repeated activation of the neural networks involved in this use may increase motor skills ${ }^{14,25}$. However, no studies have examined the influence of a specific functional task-oriented PM on (re) learning motor ADL and on motor imagery ability in individuals with chronic stroke. This study verified whether an individualized, specific functional task-oriented MP, when added to conventional PT, promoted better AOU and QOM of the paretic UL and increased kinesthetic and visual motor imagery abilities in individuals with chronic stroke. The findings demonstrated that the addition of functional MP, based upon KC added to conventional PT, resulted in greater functional gains.

Importantly, this study showed that four weeks of PT were not enough to demonstrate significant changes in the functional capacity of individuals with stable motor impairments. However, the findings supported the hypothesis that four weeks of specific functional task-oriented MP training, when added to PT, resulted in functional and clinical improvements. These functional gains were similar to a previous study, that which used the same outcome measures, but employed other interventions ${ }^{27}$. Given the employed outcomes, the chronicity of the sample, the stable motor deficits, and the amount of changes in a relatively short time frame, it is likely that these changes were attributable to the addition of the MP intervention.

MP also resulted in increases in motor imagery abilities for all subjects. The identification of the $\mathrm{KC}$ involved in the movement production may have increased motor imagery ability. The use of this cognitive strategy could improve motor learning. Stinear et al. ${ }^{28}$ suggested that kinesthetic, but not visual motor imageries, modulates corticomotor excitability. However, significant motor imagery gains were found for both the visual and kinesthetic motor imagery abilities. It is possible that the individuals used both strategies to imagine the movement during the MP training. However, these gains were not maintained after the withdrawal of MP, suggesting that these individuals improved the use of their UL, but did not need to use this cognitive strategy to perform their ADL.

Significant changes were observed for the secondary outcome variables and the results suggested that MP could improve manual dexterity and these were related to the ability to use the UL in ADL. The capacity to perform ADL is important for functional independence and is a predictor of functional recovery after stroke ${ }^{29}$. UL impairments occur in $85 \%$ of stroke patients, and six months after stroke, $26 \%$ of the survivors were dependent in their $\mathrm{ADL}^{2}$. Consistent with our hypothesis, the addition of specific functional task-oriented MP training resulted in considerable improvements in manual dexterity and in the MAL-AOU and QOM, during the performance of $\mathrm{ADL}$, and these improvements were maintained after the withdrawal of the MP intervention. Moreover, the results showed increases in gait speed. These gains suggested that specific MP could increase mobility. In addition, changes were also observed for some reported and observed variables. All subjects reported improvements related to their primary complaints, e.g., they started using their paretic UL during daily functions and decreased their UL flexion patterns during stance and gait. These postural changes and the increases in gait speed may be due to the increased use of the UL to perform manual tasks, thus reducing its need for postural adjustments. The present functional changes have potential clinical significance and suggest that such changes could be observed without intensive physical practice and/or expensive equipment, which may be impractical in clinical contexts.

It is important to note that the participants showed complete adherence to the MP intervention. This could be demonstrated by the attendance at all sessions and they even demonstrated the desire to continue. In addition, none of the subjects gave up the program. When they were asked about their preferences between conventional $\mathrm{PT}$ or $\mathrm{PT}+\mathrm{MP}$, $100 \%$ preferred the latter. These results could be related to the characteristics of the MP training, since all $\mathrm{KCs}$ were based upon functional and specific daily tasks, which could increase their motivation and participation.

One could argue that the observed gains were attributable to the potential for practice or learning effects, which could be observed when individuals repeat a task over time ${ }^{30}$. However, this effect was minimized by the time between the assessments, which were carried out at four-week intervals. Another disadvantage could be related to the sequences of the interventions and/or the carryover effects ${ }^{30}$, which 
could occur when subjects are exposed to multiple treatment conditions. However, the objective of this study was not to determine if the MP intervention was better than the conventional PT, but to investigate the effects of the addition of MP to PT.

The major advantage of this design was the ability to control for the potential influences of individual differences ${ }^{30}$, since subject characteristics, such as age, gender, and motivation, remained constant throughout the course of the study. Therefore, the observed differences between the treatment conditions were more likely to reflect the treatment effects, and not the between-subject variability. The use of subjects as their own controls provides the most possible equivalent group comparison. The $\mathrm{A}_{1}-\mathrm{B}-\mathrm{A}_{2}$ design is indicated when individuals acted as their own controls and did not limit the validity of the results. Moreover, this design could be inserted into daily clinical practice, when physical therapists need to develop and combine various strategies to improve functional capacity for individuals with stable motor deficits.

Another limitation included the relatively small sample size. However, this was not believed to be the case, since the statistical power was high for the primary outcome measures. In addition, for obvious ethical reasons, this study was limited to subjects who were willing to participate and, therefore, were a self-selected group of highly motivated individuals. This may also affect the generalizability of the present findings to the overall stroke population. Randomized controlled trials with larger samples of subjects with various levels of impairments are necessary to better control for these confounding factors.

\section{Conclusions}

The findings of the present study suggested that the addition of functional MP to conventional PT resulted in greater functional gains, regarding the AOU and QOM of the paretic UL, the kinesthetic and visual motor imagery abilities, manual dexterity, and gait speed. These gains, except for the motor imagery abilities, were maintained one month after the cessation of MP+PT, suggesting motor relearning.

\section{- Acknowledgements}

For the financial support provided by the following Brazilian funding agencies: Fundação de Amparo à Pesquisa do Estado de Minas Gerais (FAPEMIG), Brazil, Conselho Nacional de Desenvolvimento Científico e Tecnológico (CNPq), Brazil, Coordenação de Aperfeiçoamento de Pessoal de Nível Superior (CAPES), Brazil, and Santa Casa de Bom Despacho, MG, Brazil.

\section{References}

1. Lebrasseur NK, Sayers SP, Ouellette MM, Fielding RA. Muscle impairments and behavioral factors mediate functional limitations and disability following stroke. Phys Ther. 2006;86:1342-50. PMid:17012638. http://dx.doi. org/10.2522/ptj.20050162

2. Carod-Artal FJ, Egido JA. Quality of life after stroke: The Importance of a good recovery. Cerebrovasc Dis. 2009;27(suppl 1):204-14. PMid:19342853. http:// dx.doi.org/10.1159/000200461

3. Page SJ, Levine P, Leonard A. Mental practice in chronic stroke: Results of a randomized, placebo controlled trial. Stroke. 2007;38:1293-97. PMid:17332444. http://dx.doi. org/10.1161/01.STR.0000260205.67348.2b

4. Sharma N, Baron JC, Rowe JB. Motor imagery after stroke: Relating outcome to motor network connectivity. Ann Neurol. 2009;66:604-16. PMid:19938103. http:// dx.doi.org/10.1002/ana.21810

5. Braun SM, Beurskens AJ, Borm PJ, Schack T, Wade DT. The effects of mental practice in stroke rehabilitation: A systematic review. Arch Phys Med Rehabil. 2006; 87:84252. PMid:16731221. http://dx.doi.org/10.1016/j. apmr.2006.02.034

6. Sharma N, Pomeroy VM, Baron JC. Motor Imagery: A backdoor to the motor system after stroke? Stroke. 2006;37:1941-52. PMid:16741183. http://dx.doi. org/10.1161/01.STR.0000226902.43357.fc

7. Riccio I, Iolascon G, Barillari MR, Gimigliano R, Gimigliano F. Mental practice is effective in upper limb recovery after stroke: A randomized single-blind crossover study. Eur J Phys Rehabil Med. 2010;46:19-25. PMid:20332722.

8. Letswaart M, Johnston M, Dijkerman HC, Joice S, Scott CL, MacWalter RS, et al. Mental practice with motor imagery in stroke recovery: Randomized controlled trial of efficacy. Brain. 2011;134:1373-86. PMid:21515905 PMCid:PMC3097892. http://dx.doi.org/10.1093/brain/ awr077

9. Simmons L, Sharma N, Baron JC, Pomeroy VM. Motor imagery to enhance recovery after subcortical stroke: Who might benefit, daily doses, and potential effects. Neurorehabil Neural Repair. 2008;22:458-67. PMid:18780881. http:// dx.doi.org/10.1177/1545968308315597

10. Page SJ, Dunning K, Hermann V, Leonard A, Levine P. Longer versus shorter mental practice sessions for affected upper extremity movement after stroke: A randomized controlled trial. Clin Rehabil. 2011;25:62737. PMid:21427151 PMCid:PMC3257862. http://dx.doi. org/10.1177/0269215510395793

11. Rinehart JK, Singleton RD, Adair JC, Sadek JR, Haaland KY. Arm use after left or right hemiparesis is influenced by hand preference. Stroke. 2009;40:545-50. PMid:19109543. http://dx.doi.org/10.1161/STROKEAHA.108.528497 
12. Jackson PL, Doyon J, Richards CL, Maloui F. The efficacy of combined physical and mental practice in the learning of a foot-sequence task after stroke: A case report. Neurorehabil Neural Repair. 2004;18:106-11. PMid:15228806. http:// dx.doi.org/10.1177/0888439004265249

13. Guillot A, Collet C, Nguyen A, Malouin F, Richards C, Doyon J. Functional neuroanatomical networks associated with expertise in motor imagery. NeuroImage. 2008;41:1471-83. PMid:18479943. http:// dx.doi.org/10.1016/j.neuroimage.2008.03.042

14. Page SJ, Szaflarski JP, Eliassen JC, Pan H, Cramer SC. Cortical plasticity following motor skill learning during mental practice in stroke. Neurorehabil Neural Repair. 2009;23:382-89. PMid:19155350 PMCid:PMC3258452. http://dx.doi. org/10.1177/1545968308326427

15. Bertoluci PHF, Brucki SMD, Campacci SR, Juliano Y. O Mini exame do Estado Mental em uma população geral. O impacto da escolaridade. Arq Neuro-Psiquiatr. 1994;52:17. http://dx.doi.org/10.1590/S0004-282X1994000100001

16. Bohannon RW, Smith MB. Inter-rater reliability of a modified Ashworth scale of muscle spasticity. Phys Ther. 1987;67:206-07. PMid:3809245.

17. Gregg M, Hall CR, Martin KA. Measuring movement imagery abilities: A revision of the Movement Imagery Questionnaire. J Ment Imagery. 2007;21:143-54.

18. Kalra L, Crome P. The role of prognostic scores in targeting stroke rehabilitation in elderly patients. J Am Geriatr Soc. 1993;41:396-400. PMid:8463526.

19. Van der Lee JH, Beckerman H, Knol DL, De Vet HC, Bouter LM. Clinimetric properties of the motor activity $\log$ for the assessment of arm use in hemiparetic patients. Stroke. 2004;35:1410-14. PMid:15087552. http://dx.doi. org/10.1161/01.STR.0000126900.24964.7e

20. Saliba V, Magalhães LC, Faria CDCM, Laurentino GEC, Cassiano JG, Teixeira-Salmela LF. Cross-cultural adaptation and analysis of the psychometric properties of the Brazilian version of the motor activity $\log$. Panamerican J Public Health. 2011;30:262-71. http:// dx.doi.org/10.1590/S1020-49892011000900011

21. Yancosek KE, Howell D. A narrative review of dexterity assessments. J Hand Ther. 2009;22:25870. PMid:19217254. http://dx.doi.org/10.1016/j. jht.2008.11.004

22. Lourenção MIP, Tsukimoto GR, Battistela LR. O "teste de destreza manual Minnesota adaptado" utilizado como avaliação do potencial de uso de membros superiores de pacientes hemiplégicos. Acta Fisiatrica. 2007;14:56-61.
23. Nascimento LR, Caetano LCG, Freitas DCMA, Morais TM, Polese JC, Teixeira-Salmela LF. Diferentes instruções durante teste de velocidade de marcha determinam aumento significativo na velocidade máxima de indivíduos com hemiparesia crônica. Rev Bras Fisioter. 2012;16(2):122 7. http://dx.doi.org/10.1590/S1413-35552012005000008

24. Boutin A, Blandin Y. On the cognitive processes underlying contextual interference: Contributions of practice schedule, task similarity and amount of practice. Hum Mov Sci. 2010;29:910-20. PMid:20822819. http:// dx.doi.org/10.1016/j.humov.2010.07.011

25. Miyai I. Neuroscience based strategies for neurorehabilitation. Brain Nerve. 2007;59:347-55. PMid:17447521.

26. Wallace AC, Talelli P, Oliver R, Ward N, Di Lazzaro V, Rothwell JC, et al. Standardizing the intensity of upper limb treatment in rehabilitation medicine. Clin Rehabil. 2010;24:471-78. PMid:20237174 PMCid:PMC2994273. http://dx.doi.org/10.1177/0269215509358944

27. Fuzaro AC, Guerreiro CT, Galetti FC, Jucá RBVM, Araujo JE. Modified constraint-induced movement therapy and modified forced-use therapy for stroke patients are both effective to promote balance and gait improvements. Rev Bras Fisioter. 2012;16(2):157-165. http://dx.doi. org/10.1590/S1413-35552012005000010

28. Stinear CM, Byblow WD, Steyvers M, Levin O, Swinnen SP. Kinesthetic, but not visual, motor imagery modulates corticomotor excitability. Exp Brain Res. 2006;168:15764. PMid:16078024. http://dx.doi.org/10.1007/ s00221-005-0078-y

29. Richards LG, Stewart KC, Woodbury MI, Senesac C, Cauraugh JH. Movement-dependent stroke recovery: A systematic review and meta-analysis of TMS and fMRI evidence. Neuropsychologia. 2008;46:3-11. PMid:17904594 PMCid:PMC2248459. http://dx.doi. org/10.1016/j.neuropsychologia.2007.08.013

30. Portney LG, Walkins MP. Foundations of clinical research: Applications to practice. 3rd ed. New Jersey: Pearson Prentice Hall; 2009.

\section{Correspondence}

\section{Clarissa C. dos Santos-Couto-Paz}

Universidade de Brasília

Faculdade de Ceilândia

QNN 14 Área Especial, Ceilândia Sul CEP 72220-140, Brasília, DF, Brazil e-mail: clarissacardoso@unb.br 